\title{
BERTA ISLA, DE JAVIER MARÍAS: UNA LECTURA INTERTEXTUAL (DE T. S. ELIOT A HAWTHORNE Y MILTON)
}

\author{
BERTA ISLA, BY JAVIER MARÍAS: AN INTERTEXTUAL \\ READING (FROM T. S. ELIOT TO HAWTHORNE AND
} MILTON)

\section{ABSTRACT}

This article analyzes the plot of Berta Isla (2017) by Javier Marías from some literary works of the canon of English and American literature (Wakefield, by Nathaniel Hwathorne, but also the Sonnet XIX by John Milton). In addition to as «hypotexts», these works are configured as «germinative intertexts», according to the definition made by José María Pozuelo Yvancos in one of his studies on the Spanish writer. In this sense, Four Quartets, by T. S. Eliot, would embody the most emblematic and important intertext from which the other intertextuality phenomena will determine the development of the fictional plot.

Key words: Javier Marías, Berta Isla, T. S. Eliot, Hawthorne, Milton 


\section{RESUMEN}

En este artículo se analiza la trama de Berta Isla (2017) de Javier Marías a partir de algunas obras literarias del canon de la literatura inglesa y americana (Wakefield, de Nathaniel Hwathorne, pero también el soneto XIX de John Milton). Además de en cuanto «hipotextos», estas obras se configuran como «intertextos germinativos», según la definición que elabora José María Pozuelo Yvancos en uno de sus estudios sobre el escritor madrileño. En este sentido, Four Quartets, de T. S. Eliot, encarnaría el intertexto más emblemático e importante del que surgen los demás fenómenos de intertextualidad que pautan el desarrollo de la trama novelesca.

Palabras clave: Javier Marías, Berta Isla, T. S. Eliot, Hawthorne, Milton.

Fecha de recepción: 12 de marzo de 2020.

Fecha de aceptación: 29 de marzo de 2020.

Cómo citar: Candeloro, Antonio (2020), «Berta Isla, de Javier Marías: Una lectura intertextual (de T. S. Eliot a Hawthorne y Milton)», en Actio Nova: Revista de Teoría de la Literatura y Literatura Comparada, 4: 46-65.

DOI: https://doi.org/10.15366/actionova2020.4.003 


\section{INTRODUCCIÓN}

Este artículo pretende analizar de qué forma la última novela de Javier Marías, Berta Isla, publicada para Alfaguara en el 2017, entabla un discurso intertextual con Four Quartets, de T.S. Eliot, obra poética publicada en cuatro partes entre 1936 y 1942 y, de forma unitaria, para la editorial Harcourt de Nueva York, en 1943; con el relato Wakefield de Nathaniel Hawthorne (aparecido en 1835); y con el soneto XIX de John Milton (siglo XVII). A pesar de la distancia temporal entre estas obras; a pesar de los diferentes géneros a los que pertenecen (novela, lírica, relato); a pesar, también, de las diferentes poéticas que vertebran el discurso de los varios autores citados, veremos cómo sobre todo Four Quartets se configura no solo en cuanto «hipotexto» que irá pautando la trama de la novela sobre todo en sus momentos álgidos de suspense y tensión narrativa, sino también en cuanto «intertexto germinativo», tomando de José María Pozuelo Yvancos la definición que él aplica a los textos literarios en el momento en el que:

El discurso o texto origen actúa $[\ldots]$ como fuente generativa, $[\ldots]$ se comporta como estímulo de una creatividad nueva, que aun siendo deudataria del discurso o texto base (no necesariamente desde su literalidad o cita), se halla transformada y sobre todo evolucionada hacia lugares no previstos, de manera que la simple cita o referencia de la fuente no agotaría su fertilidad hermenéutica (Pozuelo Yvancos, 2018a: 101).

Como el mismo crítico explicita, se trata de una propuesta teórica y terminológica que surge a raíz del artículo de Cesare Segre «Intertestuale-interdiscorsivo. Appunti per una fenomenologia delle fonti» ${ }^{1}$. Como queda patente ya desde el título, en su propuesta Segre nos ofrece un análisis pormenorizado de qué ocurre cuando un texto se construye a partir de las citas o los fragmentos, las alusiones o las reescrituras de un texto aparecido previamente. Se trata también de un fenómeno que estudia Piero Boitani (1999) en Il genio di migliorare un'invenzione, un ensayo en el que el comparatista italiano demuestra, a través de múltiples ejemplos, cómo un escritor puede llegar incluso a «mejorar» la inventio de otro, reescribiendo precisamente su invención personal y original (es lo que ocurre, por citar tan solo un ejemplo, con Dante en el momento en el que, en su Comedia, re-inventa el final que Homero nos ofrece de la muerte de Ulises en su Odisea en el famoso canto XXVI del Infierno). Se trata de analizar cómo esas «transizioni letterarie» fomentan esa misma

\footnotetext{
1 Publicado por primera vez en 1982, reaparece en Segre, 1984: 103-118.
} 
fecundidad hermenéutica a la que hace referencia Pozuelo Yvancos, siendo la imagen que recibe el autor contemporáneo del escritor «clásico» o perteneciente al pasado un estímulo fundamental para dar riendas sueltas a una re-interpretación y una re-escritura originales de esa misma imagen y de esas mismas fuentes literarias. Si es verdad que, tal y como demuestra el mismo T. S. Eliot, el autor original se nutre y depende, en cierto sentido, del autor del pasado, también es verdad que esa herencia literaria puede funcionar como estímulo fundacional para la construcción de un texto nuevo y de un mundo de ficción del todo inédito. Es lo que ocurre en Berta Isla precisamente a través de las muchas citas literales (y no solo literales) que provienen de Four Quartets, una obra compleja que bien sintetiza el significado de la poesía y de la poética eliotiana del «talento individual» construido a partir de la «tradición» canónica del pasado².

\section{T. S. Eliot y Four Quartets; Nathaniel Hawthorne y Wakefield}

Berta Isla narra las vicisitudes de Tomás (o Tom) Nevinson y de su mujer, que da título a la obra. El primero es un estudiante superdotado para los idiomas y para las imitaciones de acentos de los demás. Berta Isla es una joven que, tras enamorarse de Tom desde la adolescencia, decide casarse con él, aunque este empiece a trabajar entre Londres y Oxford para el Foreign Office del Reino Unido. Los viajes del joven se hacen cada vez más frecuentes, hasta que Berta se da cuenta de que Tomás está involucrado también en el MI6, el servicio secreto británico para las relaciones internacionales. Dividida en diez capítulos, la novela está narrada en tercera persona de singular por un narrador omnisciente (en los capítulos I, II, VIII y IX) y en primera persona de singular por la misma Berta Isla (en los capítulos del III al VII y el último, el X) con una eficaz alternancia de voces y de puntos de vista sobre la misma trama. Si los capítulos que atañen al protagonista masculino nos desvelan cómo este acaba trabajando para el servicio exterior de inteligencia del gobierno británico, viéndose obligado a aceptar la oferta de los mismos para evitar la acusación del presunto asesinato de Janet, una joven de la que fue amante durante sus estancias oxonienses en la etapa de su carrera universitaria, los capítulos que narra en primera

\footnotetext{
${ }^{2}$ Cfr. Eliot, 1949: 15. Es importante subrayar cómo para Eliot esa misma obra del presente trastocará y modificará inevitablemente nuestra manera de leer las obras del pasado que la han inspirado: cfr. Eliot, 1955: 21: «lo que ocurre cuando se crea una nueva obra de arte es algo que les ocurre simultáneamente a todas las obras de arte que la precedieron».
} 
persona del singular la protagonista femenina nos transmiten y detallan el estado de zozobra constante que la misma Berta empieza a sufrir en el momento en el que descubre el peculiar trabajo de Tomás, obligado por ley a no desvelar nunca la verdad sobre sus operaciones clandestinas y sus actuaciones encubiertas y, al mismo tiempo, avaladas por el Estado. Berta Isla adopta los moldes de las novelas de espionaje para desmontarlos desde un enfoque filosófico a partir del cual tanto la narradora en primera persona como el narrador externo y omnisciente nos empujan a reflexionar sobre algunos de los ejes fundamentales de la poética de Javier Marías: la imposibilidad de poder saber la verdad a ciencia cierta; la imposibilidad de poder conocer a fondo a los demás, incluyendo a la propia pareja; la dificultad de seguir enamorados en el momento en el que el uno le impone al otro una cesura total sobre su segunda vida, o vida paralela, dedicada al engaño, la manipulación y la traición de los demás, en el nombre de la defensa del Estado ${ }^{3}$.

El lector se verá así envuelto en una serie de eventos de los que podrá captar tan solo algunos matices, los que desvelará el narrador omnisciente y los que Berta Isla se empeñará en desenredar a partir de la postura hermética de su marido, de sus silencios y de sus desapariciones a lo largo del tiempo (siendo la más larga de una duración de doce años).

Es fácil comprobar también cómo Berta Isla juega con el esquema estructural de la Odisea dándonos una versión contemporánea y actualizada de la misma: si Ulises, en la obra de Homero, tardará diez años en poder volver a Ítaca y así abrazar a Penélope para en seguida narrarle todas sus desventuras en el mismo lecho matrimonial (elemento fundamental y funcional en la fase del reconocimiento o anagnórisis de la parte final de la Odisea $)^{4}$, en Berta Isla, al contrario, el nuevo Ulises, Tomás Nevinson, volverá a casa tras doce años de ausencia «justificada» en el nombre de la defensa del Reino Unido (y de las guerras «sucias» que este lleva a cabo a lo largo de los años 70, 80 y 90), para evitar narrarle a su Penélope sus artimañas y esclarecerle de una vez por todas el misterio de una ausencia tan larga y tan aparentemente inaceptable. Está claro, también, que, si la Odisea encarna la

\footnotetext{
${ }^{3}$ Está claro que el lector atento de Tu rostro mañana (novela aparecida en tres tomos entre el 2002 y el 2007) podrá reconocer muchos rasgos en común entre esta novela y la anterior: Pittarello (2018: 45-48) subraya las fructíferas discrepancias cronológicas del 'tiempo de la narración' entre una y otra obra, a pesar de la presencia de los mismos personajes, como Peter Wheeler y Bertram Tupra: el primero es un Profesor de Literatura Española que le pedirá ayuda a Tomás Nevinson para pulir sus textos académicos en castellano; el segundo irá convirtiéndose en su jefe dentro del mundo de los servicios secretos paralelos al MI6, además de en el único contacto «real» entre ese mundo y el de Berta Isla que todavía espera la vuelta de su marido en Madrid. En resumen: Berta Isla encuadra a los mismos personajes que serán centrales en Tu rostro mañana unos treinta años antes de sus actuaciones en esa novela central del así llamado «Ciclo de Oxford», compuesto también por la novela fundacional Todas las almas (1989), y la «falsa novela» Negra espalda del tiempo (1998) (cfr. Pozuelo Yvancos, 2018b y Blanca, 2017: 11-15).

${ }^{4}$ Cfr. Boitani, 2014: 64-132.
} 
exaltación del amor conyugal, Berta Isla nos relata los altibajos de una relación matrimonial en la que, aun permaneciendo en la espera y estando enamorada de su marido, la nueva Penélope entretiene esa misma espera con hombres que no dejarán huella y, finalmente, no borrarán al fantasma del pasado del marido desaparecido durante tanto tiempo ${ }^{5}$.

Pero si la literatura clásica parece subyacer en la estructura misma y en el andamiaje narrativo de la obra, serán, en cambio, la literatura inglesa y la americana los ejes alrededor de los cuales los protagonistas y los dos narradores principales irán hilvanando su discurso y sus tramas paralelas, dando lugar a fenómenos intertextuales de carácter verdaderamente «germinativo».

Intentado captar las intenciones de su pupilo, y consciente de sus grandes dotes para los idiomas y las imitaciones de los demás, Peter Wheeler le cuenta a Tomás Nevison

\footnotetext{
${ }^{5} \mathrm{Si}$ en la p. 300 es el mismo Tomás quien cita implícitamente a Homero, y su Ilíada: «¿Y cómo crees que se ganó la guerra de Troya? ¿Qué fue el caballo sino una estratagema, un regalo envenenado, un engaño?», para exaltar la función de los servicios secretos para el bien de los demás (y por eso mismo reafirma que «La culpa es del que se deja burlar, no del que burla, porque su obligación es hacerlo», Marías, 2017: 300), en la p. 351 serán la misma Berta y Bertram Tupra (uno de los jefes de Tomás) quienes evocarán la situación existencial de Penélope: Berta le pregunta retóricamente a Tupra: «¿Y qué debo hacer yo mientras tanto? ¿Me pongo de luto o continúo aguardando? ¿He de considerarme viuda o aún estoy casada? ¿Mis hijos tienen padre o se han quedado huérfanos? ¿Cuánto tiempo pasará?»; Tupra le contesta a Berta: «Piense en las mujeres de los marinos que tardaban años en regresar o no regresaban y de los que nada se sabía en pasados siglos», para luego poner inmediatamente el ejemplo de Ulises. El diálogo intertextual prosigue en la p. 383, cuando Berta amplía el punto de vista de Tupra y reconoce ante sí misma y en su fuero interno que «La historia había estado llena de mujeres que se quedan y esperan, que miran hacia el horizonte todos los días al atardecer tratando de divisar una figura familiar [...]», para luego reconocer también que esto ocurría no solo en el caso de Ulises, sino también en el de «cuantos se habían embarcado hacia Troya y habían asediado durante años la ciudad, inaugurando así las largas ausencias de la literatura y por tanto de la realidad (sólo existe lo que se nos cuenta, lo que se alcanza a contar)». Pero las referencias al «hipotexto» pueden ser reescrituras de ese texto de partida: en esa misma p. 383, Berta Isla se pregunta, a propósito de la vida elegida por Tomás: «[...] ¿por qué había elegido aquella absurda existencia, por qué había optado por una doble vida que lo alejaba de mí, hasta convertirse en una hoja de otoño que se balancea y cae?». Se trata de una reescritura de los famosos vv. 145149 del canto VI de la Ilíada (Homero, 1996: 217: «iMagnánimo Tidida! ¿Por qué me preguntas mi linaje? / Como el linaje de las hojas, tal es también el de los hombres. / De las hojas, unas tiras a tierra el viento, y otras el bosque / hace brotar cuando florece, al llegar la sazón de la primavera. / Así el linaje de los hombres, uno brota y otro se desvanece» (sobre la larga tradición de estos versos, cfr. Cristóbal, 2015: 285-289 y, sobre todo, Curtius, 2014: 125-134). La Ilíada reaparecerá en el cap. VII (Marías, 2017: 411-412), cuando Berta Isla se acordará del caso de Príamo, quien «vio morir con sus ojos a su primogénito, Héctor, morir a hierro, y por eso fue a suplicarle a Aquiles que le entregara su cuerpo arrastrado y maltrecho para darle sepultura; si se avino a humillarse fue por certeza, porque le constaba»; Berta alude al famoso canto XXIV del poema para subrayar la importancia de poder confirmar que alguien haya muerto de verdad y se pueda comprobar teniendo delante al cadáver; si ella sigue dudando hasta el final del nóstos (o regreso) de Tomás a Madrid es precisamente por no haber contemplado todavía su cadáver. Enésima referencia a la mitología en la p. 435: al preguntarle Tomás al Profesor Mr Southworth sobre su colega y maestro Peter Wheeler, este contesta citando verbatim sus reflexiones sobre el acercase de la hora final: «[Estoy] Esperando una visita de la Parca, a ser posible una indolora y de aviso [...]»; en la p. 438, en cambio, será el mismo Tomás en citar al mismo personaje mitológico delante de $\mathrm{Mr}$ Southworth, pero en una acepción totalmente negativa: «Yo, en cambio, los he pasado [estos años] esperando a la Parca, cualquier día, a cualquier hora, con unas pocas treguas de vez en cuando. Pero uno sabe que son sólo eso, treguas, y no descansa». Personificaciones de la Muerte a partir de otras referencias artísticas -como el cuadro Las Edades y La Muerte de Hans Baldung Grien, de 1541-1544ya aparecían y se ampliaban en algunas ekfrasis perturbadoras en Tu rostro mañana: para un análisis de las mismas, cfr. Candeloro, 2016: 245-262.
} 
la importancia que siempre han tenido los servicios secretos para el buen funcionamiento de los estados democráticos, aun cuando aparentemente no se vive en épocas de guerra, como sí lo fueron las dos guerras mundiales que él presenció (habiendo nacido en 1913 en Nueva Zelanda y habiendo participado activamente en función de agente secreto según los rumores difundidos en la Universidad de Oxford - Marías, 2017: 54); solo así, y desde el punto de vista del Profesor Wheeler, los seres humanos pueden intentar modificar o influenciar el universo, actuando en la retaguardia e influyendo en secreto:

Si hay algo que caracteriza y une a la mayoría de la humanidad (y al decir esto me refiero a cuantos han pasado por la tierra desde tiempos inmemoriales), es que a todos nos influye el universo sin que nosotros podamos influir en él lo más mínimo, o apenas. Aunque creamos formar parte de él, aunque estemos en él y nos afanemos por variar algún detalle a lo largo de nuestros días, en realidad somos desterrados del universo, como dijo aquel cuento célebre sobre el hombre que se borró del mundo con tan solo mudarse de calle y guardar silencio al respecto - 'Outcast of the universe', esa fue la expresión que empleó en inglés, y la repitió, como si le diera que pensar e hiciera mucho que no la recordaba - 'Outcast of the universe' (Marías, 2017: 65).

Tomás Nevinson imagina que se trata de una cita literaria; Peter Wheeler, su maestro, imagina que él sabe perfectamente a qué «cuento célebre» se está refiriendo ${ }^{6}$. Se trata de la frase que cierra el arriba citado relato Wakefield, de Nathaniel Hawthorne y aparecido en 1835. Esta es la cita completa:

Amid the seeming confusion of our mysterious world, individuals are so nicely adjusted to a system, and systems to one another and to a whole, that, by stepping aside for a moment, a man exposes himself to a fearful risk of losing his place forever. Like Wakefield, he may become, as it were, the Outcast of the Universe (Hawthorne, 1969: 162).

La frase sintetiza y resume parte del misterio del relato de Hawthorne: ¿qué puede empujar a un hombre a abandonar a su mujer y su hogar para alquilar una buhardilla en la misma calle en la que sigue viviendo su familia? Por lo visto, el narrador en primera persona que cuenta esta historia tan absurda declara hacerlo partiendo de una noticia sacada del periódico o de alguna vieja revista que la presenta como si fuera una «historia real»:

In some old magazine or newspaper I recollect a story, told as truth, of a man let us call him Wakefield- who absented himself for a long time from his wife. The fact, thus abstractedly stated, is not very uncommon, nor -without a

\footnotetext{
${ }^{6}$ En el plano de la ficción, aunque ambos sean hispanistas, esto no quita que un lector «fuerte» como Wheeler confíe en que también su alumno lo sea; en el plano de la realidad, sabemos que Javier Marías, además de ser un lector «fuerte» y «omnívoro», se licenció en Filología Inglesa y de sobra son conocidas sus traducciones de clásicos ingleses al español (a partir de la que realizó con 26 años del Tristram Shandy sterniano).
} 
proper distinction of circumstances- to be condemned either as naughty or nonsensical. Howbeit, this, though far from the most aggravated, is perhaps the strangest, instance on record, of marital delinquency; and, moreover, as remarkable a freak as may be found in the whole list of human oddities (Hawthorne, 1969: 151-152).

La extrañeza del caso depende precisamente de la postura de Wakefield: desaparecer por completo del horizonte vital y cotidiano de su familia, para ir a vivir en un piso de alquiler ubicado en la misma calle en la que vive su mujer. Por lo visto, y como se lee en el final del relato, basta con «step aside for a moment» del sistema (en este caso, el sistema familiar, el hogar cotidiano en el que se vive junto con los hijos y la propia mujer) para -igual que Wakefield- «loose his place for ever», esto es, convertirse exactamente en lo que Peter Wheeler define como «outcasts of the universe», esto es, en unos «desterrados del universo» ${ }^{7}$. Precisamente así, según Wheeler, «al hacerse invisible y borrarse», al «desaparecer para su mujer y sus allegados», al «marcharse y sustraerse» (Marías, 2017: 66), pudo dejar de ser un «desterrado del universo» y empezar a ser alguien que sí perturba o modifica (aunque mínimamente) el Universo. El personaje se mueve en el ámbito de la literatura americana del siglo XIX para tratar de convencer a su estudiante ducho para los idiomas para que empiece a mirar el mundo del espionaje desde una perspectiva nueva (además de peculiar y original): Wakefield se configura así no solo como «hipotexto», sino también, y sobre todo, en cuanto «input narrativo» para empatizar con las actividades de los que se marchan y desaparecen, de los que se auto-exilian para luchar por la defensa del Estado ( $\mathrm{y}$ aplicando en esa lucha la traición y el engaño, exactamente igual que lo hizo Ulises con el caballo de Troya). Está claro también que el lector que relea la novela se dará cuenta inmediatamente de que Tomás Nevison es una nueva re-encarnación del símbolo del «desterrado del universo»: es un Wakefield que, obligado a vivir en un pueblo cerca de Londres, abandona a su mujer legítima, y construye una nueva familia junto con Meg, una

\footnotetext{
${ }^{7}$ No podemos evitar subrayar cómo en el texto original el término se presenta en singular (no en plural) y en mayúsculas, como si Wakefield fuera de verdad el símbolo que encarna (a los ojos del narrador anónimo que arranca el relato con «I») esa clase de «desterrados» del Universo; como si Wakefield fuera, en suma, el «desterrado» por antonomasia (la paradoja existencial del personaje siendo la de haber perdido «his place and privileges with living men, without being admitted among the dead» (Hawthorne, 1969: 160). Pero las citas a Ulises y las alusiones explícitas o implícitas a la Ilíada y a la Odisea (tanto por parte de Berta Isla, como por parte de Bertram Tupra, Tomás Nevinson y el mismo Peter Wheeler) nos demuestran que no es así y que, en el ámbito de la literatura occidental, la historia de los «desterrados del Universo» se remonta a épocas muy anteriores a la de Hawthorne. Otros dos ejemplos que se citan en la novela: Le colonel Chabert, de Honoré de Balzac, novela corta aparecida en 1832 (esto es, en fecha muy cercana al Wakefield de Hawthorne) y The Wife of Martin Guerre, de Janet Lewis, publicada en 1941 y cuya reedición en español se debe precisamente a Javier Marías: cfr. Lewis, 2016 (en la misma editorial redondina habían aparecido sendas obras de la misma autora: Lewis 2015 y Lewis 2017).
} 
enfermera que nada sabe de él ni de su pasado (llegando incluso a tener una hija de la misma). Si en Madrid Berta Isla y sus dos hijos creerán ser respectivamente una viuda y unos huérfanos, en el pueblo anónimo cerca de Londres Tom pasará a llamarse Mr James Rowland y a ser un modesto profesor de lenguas en una escuela de secundaria. Los doce años que pasará en esa especie de limbo los sintetizará recordando exactamente las palabras de Wheeler, pero para darle un sentido completamente diferente: si Wakefield, en el texto original, perturba el universo al convertirse en un «desterrado» del mismo, Tomás Nevinson, cuando se verá obligado a vivir de incognito, se convertirá en un Wakefield que no actúa ni perturba nada: «Resulta que lo que me interesa y me salva es que se me crea muerto y que nadie me recuerde» (Marías, 2017: 444). Es más, cuando empieza su relación con Meg, adopta exactamente la misma táctica de Wakefield: al no hablarle nunca de su pasado, y al no hacer nunca referencia a sus familiares, Tomás se verá obligado a fingir viajes desde la ciudad de provincia a Londres, hasta que se aburra y opte por esconderse en el mismo sitio: «en realidad me metía en un hotel dos o tres noches y apenas salía de la habitación durante el día, por si tenía la mala suerte de encontrármela por la calle, cuando se me suponía ausente» (Marías, 2017: 447). Esto es: Tomás finge ser «doblemente muerto»: para Berta Isla y sus hijos, al no volver a comunicar con ellos; para Meg, en el principio de su relación con ella, al quedarse en la misma ciudad de provincia para fingir visitas hacia familiares que no existen ${ }^{8}$. El secreto se convierte en condena y, al mismo tiempo, en forma de vida que puede empujar al ser humano a estar «fuera del sistema»o «de los sistemas» que evoca el narrador de Wakefield cuando, en el íncipit, subraya la anomalía de la historia del mismo personaje.

Sin embargo, la trama se desarrolla y arranca también gracias a otro autor, el poeta americano naturalizado inglés T. S. Eliot, el autor de The Waste Land (1922).

Cuando Tomás viene interrogado dentro del despacho de Mr Southworth (otro profesor amigo que lo aprecia) por un policía que parece señalarlo como el principal sospechoso del asesinato de Janet Jefferys, joven empleada de una de las muchas librerías de Oxford y amante de Nevinson durante sus estancias de estudiante universitario, Southworth le recomienda hablar con Peter Wheeler porque parece ser que solo este podrá ayudarlo a salir indemne del asunto criminal. Peter, a su vez, le dará instrucciones sobre cómo entrar en contacto con Bertram Tupra, uno de los agentes del mismo servicio secreto

\footnotetext{
8 Tampoco es casualidad que, antes de su regreso a Madrid, y tras abandonar a Meg y su hija, Tomás permanezca durante un tiempo en otro apartamento londinense ubicado en Dorset Square, «al lado de Baker Street» (Marías, 2017: 470): esto es, al lado de la calle del piso de Sherlock Holmes.
} 
con el que el anciano académico colaboró en su juventud, en la librería Blackwell’s. ¿Pero cómo podrá Tomás reconocer a Tupra? Esta es la respuesta de Wheeler:

Ponte a hojear algún libro de Eliot. Él hojeará uno también'. '¿̇T. S. Eliot o George Eliot?'. 'El poeta, Tomás, el poeta, tu tocayo', le contestó Wheeler con un asomo de exasperación. 'Cuatro cuartetos, La tierra baldía, Prufrock, lo que se te antoje’ (Marías, 2017: 100).

Si Wakefield pasa a convertirse en «símbolo» de la parábola existencial de Tomás Nevinson a lo largo de toda la novela, los poemas de T. S. Eliot y, en particular, Little Gidding, el último de los Four Quartets, pasarán a convertirse en «gérmenes» de algunas de las imágenes más inquietantes y perturbadoras de la novela?

\section{T. S. Eliot en el idiolecto de Berta Isla}

Un rasgo típico del estilo de Marías, y que, como vamos comprobando, también aparece en Berta Isla, estriba en el hecho de que las citas textuales o las alusiones literarias (más o menos explícitas, más o menos veladas) pasan a formar parte del idiolecto de los varios personajes ${ }^{10}$. Es como si el T. S. Eliot de los Four Quartets que el lector empieza a conocer a través de la lectura errática de Tomás Nevinson contagiara también el lenguaje y la peculiar forma de expresarse de los demás, a partir tanto del narrador omnisciente y externo, como de la misma voz de Berta Isla, que se expresa y cuenta en primera persona del singular. Los versos de Four Quartets germinarán en cuanto «fragmentos» del idiolecto de las dos instancias narrativas. Veamos algunos ejemplos, antes de pasar a las reflexiones conclusivas.

\footnotetext{
9 Tal y como analiza Candeloro (2020) (en prensa) estudiando en detalle los versos de Little Gidding que Tomás Nevinson irá traduciendo, parafraseando e introduciendo en su narración y rememoración de los hechos pasados.

${ }^{10}$ Pero los personajes también se contagian otros elementos, además de su peculiar forma de expresarse desde el punto de vista lingüístico: la cicatriz en la barbilla que tanto llama la atención de Tomás Nevinson al conocer al Profesor Wheeler la tendrá él también en una mejilla, al entrar a formar parte del mundo de Bertram Tupra tras un accidente del que Tomás no dará ulteriores detalles: cfr. Marías, 2017: 60: «La marca arrancaba cerca de la comisura izquierda y corría vertical -o algo en diagonal- hasta el final del mentón, lo cual hacía parecer que ese lado de su cara [de Peter Wheeler] jamás sonreía (aunque lo hiciera), y le daba un aire levemente mohíno o sombrío»; y cfr. Marías, 2017: 161: «[...] tras una ausencia de dos meses y pico volvió marcado, quiero decir con una visible cicatriz en una mejilla, un corte producido no por una cuchilla de afeitar sino por una navaja o un puñal». La cicatriz es la señal (incluso física) de que Tomás ha sido ya marcado de por vida por su nuevo papel de espía (aunque luego un cirujano plástico se la elimine para no llamar la atención del enemigo y favorecer sus múltiples metamorfosis).
} 
La primera vez que Berta Isla citará a Eliot será en la primera sección del capítulo IV: tras una espeluznante amenaza de muerte a su hijo Guillermo por parte de los Kindelán, una pareja de presuntos espías al sueldo del IRA, Berta decide interrumpir el silencio al que la condena su marido para llamar y avisar a Bertram Tupra, su único referente en el ámbito del servicio secreto al que está afiliado Tomás. Estos son los versos que evoca Berta al recordar el acto de Mr Kindelán, a punto de prenderle fuego al bebé con un mechero Zippo:

Aquella mañana $[\ldots]$ había estado en un tris de ver arder a mi hijo, 'Y cualquier acción es un paso hacia el fuego', le había oído recitar a veces a Tomás, de un poema que se sabía, lo murmuraba para sus adentros en inglés (Marías, 2017: 205).

Se trata del verso 12 de la V sección (la última) de Little Gidding, verso que, igual que en el caso de Tomás, funciona como premonición aciaga de un peligro inminente (en el caso del protagonista masculino de la acusación de asesinato de Janet; en el caso de la protagonista femenina de la potencial muerte «por fuego» y entre llamas de Guillermo, todavía bebé) ${ }^{11}$. Pues bien, a partir de este momento, los versos de los Four Quartets empezarán a formar parte de manera estable del idiolecto de Berta Isla; aunque también tenemos que subrayar que las citas casi nunca serán literales y hay veces en las que Berta citará versos que nunca hemos visto traducidos ni tampoco citados por parte de Tomás. Es lo que se deduce de este fragmento:

En estas oscilaciones me sentía tan ahogada que en mi cabeza se repetía otro de los versos que Tomás recitaba a veces distraídamente, por ejemplo mientras se afeitaba, en ocasiones canturreaba y en otras murmuraba aquellos versos memorizados, muchos y largos, no estaba segura de si eran todos del mismo poema ni del mismo poeta, sabía que algunos eran de Eliot, eso sí, al que leía a menudo, en voz alta a veces y a toda velocidad, y cuándo diablos lo volvería a ver. Ese verso resonaba en mí ahora: 'Esta es la muerte del aire', decía. [...] Y al cabo de unas líneas más que yo no entendía ni por tanto recordaba, Tomás añadía: 'Esta es la muerte de la tierra', 'This is the death of earth'. Y tras unos cuantos versos más venía la condena de los otros dos elementos: 'Esta es la muerte del agua y el fuego', [...] Pero el que a mí me rondaba era el primero, 'This is the death of air', así lo recitaba en inglés (Marías, 2017: 212).

\footnotetext{
${ }^{11}$ Cfr. Eliot 2002: 208: «And any action / Is a step to the block, to the fire, down the sea's throat». Como se ve, Berta se salta algunos fragmentos de los versos 12-14 que Tomás evocará a lo largo de la narración; en la rememoración de su mujer desaparecen precisamente aquel tajo» (the block), aquel «fuego» (the fire) y aquella «garganta del mar» (the sea's throat) que tanto obsesionarán a su marido: los tres elementos siendo interpretables como objetive correlatives ominosos del futuro aciago de Tomás en cuanto espía al servicio del MI6.
} 
Son versos que siguen a los que abren la II sección de Little Gidding: v. 8: «This is the death of air», v. 16: «This is the death of earth»y, finalmente, v. 24: «This is the death of water and fire» (Eliot, 2002: 181-182). El «contagio citacionista», por así decirlo, se desarrollará a partir de estos fragmentos relacionados con la angustia existencial de Berta Isla pautando la trama hasta la última página. Pero, como adelantamos, también atañe al narrador exterior omnisciente que cita los pensamientos de los demás personajes y recuerda exactamente las citas eliotianas que éstos manejan.

Un ejemplo muy evidente de este tipo de contagio citacionista aparece en el cap. II, cuando Bertram Tupra explicita una debilidad humana que compartimos desde tiempo inmemorial: los vivos creen que los muertos puedan sufrir, o preocuparse por su vida pasada, una vez muertos. Para Tupra es «la superstición de seguir atribuyéndoles propiedades y reacciones de los vivos», porque «nuestra imaginación no da para más». Sin embargo, se trata de una ilusión, justamente porque «el abismo es demasiado profundo y ahora ya no les importa nada de lo que quisieron en vida, ni siquiera lo último» (Marías, 2017: 135); de hecho, remarca Tupra, «No pueden sentir impaciencia, ni tener deseos» (136). ¿Cuál será la reacción de Tomás? La negación de esta evidencia a partir de los versos de Little Gidding: «"No es eso lo que piensa el poeta”, pensó Tom rápidamente. "Y lo que los muertos no sabían expresar, cuando vivían", recordó, "te lo pueden contar, al estar muertos"» (136; Eliot, 2002: 208) ${ }^{12}$.

Pero si T. S. Eliot resulta tan importante para la trama de Berta Isla es también porque, a través de sus Four Quartets el poeta dialoga con otros autores clásicos de la literatura inglesa. Además de la referencia al relato de Hawthorne, Wakefield, la reflexión asistemática y aparentemente filosófico-teológica del poeta alrededor del enigma del tiempo y de las relaciones entre los vivos y los muertos se verá amplificada y ampliada, en la novela, a través del diálogo intertextual (y germinativo) con William Shakespeare, Charles Dickens y, sobre todo, John Milton ${ }^{13}$. Es lo que veremos a continuación.

\footnotetext{
12 Enumeramos las páginas en las que se hace directa o indirecta alusión a T. S. Eliot: Marías, 2017: 102-104, 136, 141-142, 205, 212, 231-232, 257, 263, 278, 310, 349, 351, 357-358, 363, 367-368, 376, 380, 386, 416-417, 423-424, 467, 474-475, 482, 496, 507, 512, 518, 527.

${ }^{13}$ Por razones de espacio, dejaré para otra intervención el análisis del carácter germinativo de estos otros textos del canon inglés. De momento, nos limitamos a señalar las páginas en las que aparecen: el drama histórico Henry $V$ de William Shakespeare será motivo de debate entre Berta Isla y Tomás Nevinson en las páginas 283, 347 y 439 (el Rey se hace pasar por soldado raso la noche anterior a la batalla decisiva contra el enemigo para averiguar el grado de confianza y de lealtad de sus súbditos; según Berta es una artimaña y una trampa injustificable; según Tomás es una técnica del todo legítima para la defensa del Reino); el cuento ya comentado Wakefield de Nathaniel Hawthorne aparece en las páginas 65, 368, 444 y 447 y será fundamental también para la fenomenología del tiempo de «los que están y esperan», además de los muertos que vuelven a
} 


\section{T. S. Eliot y John Milton}

Si T. S. Eliot constituye una fuente inagotable de variaciones sobre el mismo tema (como si los versos de Four Quartets se convirtieran, de repente, en ritornelli que pautan la trama de la novela dándole aquel ritmo peculiar en el que algunas citas del narrador externo y omnisciente se solapan y reproducen en el idiolecto de la narradora en primera persona de singular), también es evidente cómo el poeta americano naturalizado inglés no es el

la vida en las páginas 416-417; la noche en la que se acostará por última vez con Tomás Nevinson, la joven Janet Jefferys estará leyendo con interés The Secret Agent (1907) de Joseph Conrad (p. 80 y, luego, p. 493), lo que podría interpretarse como sutil «ironía teatral», cuando se termina la lectura de la novela, sobre todo si tenemos en cuenta que es a partir de ese momento y de la escenificación del presunto asesinato de la misma amante, cuando Tomás entrará a formar parte del mundo del espionaje británico (el mismo que describe en detalle Conrad en su novela); para hablar de las relaciones entre vivos y muertos se citan tanto Honoré de Balzac, con su Le colonel Chabert (pp. 97, 132, 353, 374, 376) como Janet Lewis, con su The Wife of Martin Guerre (pp. 374-376); tampoco faltan Robert L. Stevenson (pp. 339, 377, 540, 543); Samuel Beckett (pp. 128-129), para la descripción del papel de los espías; William Faulkner (p. 404), para una meditación sobre el enigma del tiempo; Carl C. Lewis (p. 117) y Tolkien (pp. 113 y 331), ambos alumnos y, luego, eminentes profesores de Literatura Inglesa en la Universidad de Oxford; Erwin Panofsky (p. 111), por el ensayo Tomb Sculpture: Four Lectures on its changing aspects from Ancient Egypt to Bernini, de 1964; tampoco podemos olvidar que, a lo largo de los años, Berta Isla será profesora asociada de Lengua y Literatura Inglesa en la Universidad Complutense de Madrid: de ahí que se dedique a traducir, entre otros, a Herman Melville y algunos fragmentos complejos de Moby Dick (1851) en las pp. 341, 342, 528, además de al Charles Dickens de A Tale of Two Cities (de 1859) en las pp. 540 y 543. A propósito de esta novela, ambientada en el periodo de la Revolución Francesca entre las dos ciudades evocadas implícitamente en el título, París y Londres, es interesante notar cómo la primera cita de Berta Isla modifica el texto original: cfr. Marías, 2017: 540-541: «“toda criatura humana está destinada a constituir un profundo secreto y misterio para todas las otras. Es una consideración solemne que, cuando llego a una gran ciudad de noche, cada una de esas casas arracimadas lóbregamente encierra su propio secreto; que cada habitación en cada una de ellas encierra su propio secreto; que cada corazón palpitante en los centenares de millares de pechos que allí se esconden, es, en algunas de sus figuraciones, un secreto para el corazón más próximo, el que dormita y late a su lado. Y hay en todo ello algo atribuible al espanto..."». Dickens no habla de «espanto», sino directamente de «Muerte» (además, con mayúscula): cfr. Dickens, 1910: 11-12 (Chapter III, «The Night Shadows»): «A wonderful fact to reflect upon, that every human creature is constituted to be that profound secret and mystery to every other. A solemn consideration, when I enter a great city by night, that every one of those darkly clustered houses encloses its own secret; that every room in every one of them encloses its own secret; that every beating heart in the hundreds of thousands of breasts there, is, in some of its imaginings, a secret to the heart nearest it! Something of the awfulness, even of Death itself, is referable to this»; el uso del clímax convierte el fragmento en un excelente ejercicio de estilo poético, como en otros fragmentos de la novela. También es interesante notar que uno de los protagonistas, el francés Charles Darnay, se establece en Inglaterra como profesor experto de Lengua y Literatura Inglesa. Es más, antes de verse involucrado en el mundo del espionaje inglés y francés, viajará constantemente entre Londres y Cambridge precisamente por sus dotes de angloparlante: cfr. Dickens, 1910: 129: «A certain portion of his time was passed at Cambridge, where he read with undergraduates as a sort of tolerated smuggler who drove a contraband trade in European languages, instead of conveying Greek and Latin through the Custom-house. The rest of his time he passed in London». Tanto sus habilidades lingüísticas, como sus andanzas entre Londres y Cambridge, como sus operaciones de espionaje entre París y Londres, parecen mantener cierta similitud con la parábola existencial de Tomás Nevinson, que consigue trabajar en Inglaterra justamente por sus altas dotes lingüísticas, lo que lo lleva a moverse y viajar entre Oxford y Londres y, al entrar a formar parte del MI6, entre Londres, Madrid y el resto del globo. Cfr. también la versión española: Dickens, 2004: $83 ; 215-216$ 
único autor que, perteneciendo al canon inglés, da la pauta de las reflexiones y los pensamientos más sombríos o emotivos de los personajes protagonistas ${ }^{14}$.

En su tanteo del carácter de Tomás Nevinson, después de citar a Wakefield de Hawthorne y justo después de citar a T. S. Eliot, el Profesor Wheeler cita otros versos que su alumno favorito no consigue decodificar; refiriéndose al servicio secreto, Wheeler subraya: «Nosotros siempre estamos y esperamos» - 'We always stand and wait', fue la frase en inglés, y sonó como si fuera una cita o una referencia a algo-》 (Marías, 2017: 72).

Efectivamente, Tomás no anda desencaminado, porque sin él saberlo a ciencia cierta ni poder descubrirlo o comprobarlo a lo largo de la novela (tal y como sí le ocurre a Berta Isla con respeto a Four Quartets de T. S. Eliot, cuando esos versos se convierten en la «banda sonora» personal de su marido), se trata, efectivamente, de una especie de cita o, mejor dicho, de re-escritura (o paráfrasis) del último verso del soneto XIX de John Milton, el autor de Paradise Lost (1658-1660):

Sonnet XIX:

When I consider how my light is spent, Ere half my days, in this dark world and wide, And that one talent which is death to hide Lodged with me useless, though my soul more bent

To serve therewith my Maker, and present

My true account, lest he refurning chide,

"Doth God exact day-labor, light denied?"

I fondly ask. But Patience, to prevent

That murmur, soon replies: "God doth not need

Either man's work or his own gifts; who best

Bear his mild yoke, they serve him best. His state

Is kingly: thousands at his bidding speed,

And post o'er land and ocean without rest;

They also serve who only stand and wait (Milton, 1990: 189-190).

Como esclarece en nota Bush, el «they» al que se refiere Milton hay que interpretarlo como «los ángeles», esto es, como «all angels as God's envoys, some being sent to missions, others waiting to be sent» (Milton, 1990: nota 14, 190). Se trata de una curiosa re-escritura por parte de Javier Marías del verso del poeta del siglo XVII: si para Milton, que en este texto se queja de su ceguera y de que por eso mismo ya no puede serle útil a Dios, aunque «Patience» (la Paciencia, aquí entendida en cuanto emblema o símbolo

14 Tampoco es casualidad que, en Tu rostro mañana, Peter Wheeler esté leyendo precisamente Little Gidding cuando descubre a Valèrie, su mujer, en el acto de suicidarse disparándose en la sien: cfr. Marías, 2007: 667668: "“Ash on an old man's sleeve... This is the death of air... the constitution of silence... What we call the beginning is often the end..." (como se ve, en este caso, el Profesor Wheeler no traduce los versos originales). 
alegórico) le diga todo lo contrario y que «they also serve who only stand and wait» («también sirven los que solo están y esperan»), para Marías los espías a los que hace referencia explícita Peter Wheeler son como esos ángeles aludidos por Milton precisamente porque nunca desaparecen del todo, porque, igual que el Wakefield de Hawthorne, «siempre están y esperan».

Es lo que el mismo Tomás aprenderá a hacer de forma brillante en su papel de espía al sueldo del MI6 y bajo la coordinación de Bertram Tupra. Y es lo que aprenderá a su pesar la misma Berta Isla, condenada a «stay»y «wait», a «estar»y a «esperan» por el amor hacia su marido y por culpa de su vida «paralela».

Son versos fundamentales, estos de Milton, también porque $-\mathrm{y}$ no puede ser casualidad- cierran la novela: «Eso es lo que suele pasar con las vidas que, como la mía y también la suya, en realidad como tantas y tantas, solamente están y esperan» (Marías, 2017: 544).

Pero si nos llaman la atención es también porque no es la primera vez que Marías recurre a Milton y su soneto más íntimo y desgarrador, justamente porque en él el poeta habla abiertamente de su ceguera. «We always stand and wait» es un verso que se repite a sí mismo Casaldáliga, el protagonista de El siglo, novela que Marías publica en 1983, esto es, treinta y cuatro años antes de escribir Berta Isla.

En esta novela, tal y como explica Candeloro en el ensayo Javier Marías y el enigma del tiempo:

Marías se enfrenta por primera vez con la temática del engaño y de la traición, a partir de los recuerdos personales de su padre. Se trata de las bases de las que surgirán tanto Corazón tan blanco y Mañana en la batalla piensa en mí, como Tu rostro mañana, obra estrictamente ligada a El siglo justamente por la presencia, en ambas novelas, de los recuerdos personales de Julián Marías (Candeloro, 2016: 63).

En El siglo la huella de la poesía de John Milton aparece explícitamente en dos ocasiones: en el capítulo IV, titulado «La enfermedad», en el que el narrador externo nos relata la extraña relación sentimental entre Casaldáliga y Constanza Bacio, con la que se casa precisamente porque sabe que una enfermedad incurable determinará su muerte; y en el capítulo VI, titulado «Lisboa», en el que se nos cuenta la nueva vida de auto-exiliado de Casaldáliga, que transcurre los tres años que dura la guerra civil que destroza su país natal vagabundeando por la capital portuguesa. 
Si en el primer caso Casaldáliga pretende consolar a Constanza a través del soneto XXIII de Milton, en el segundo caso el protagonista intenta justificar su postura inerte y de indiferencia absoluta hacia la contienda a través del ya citado soneto XIX:

Siempre en silencio, en el silencio arraigado de su hogar conyugal, decidió perseverar en su espera, y así, por ejemplo, la distraía y fortalecía leyendo y releyendo el soneto de Milton sobre su mujer difunta, y sabiéndoselo de memoria, no dejaba de sentirse conmovido e identificado cada vez que llegaba a los versos finales, cuando al inclinarse la muerta soñada para abrazar al poeta ciego que nunca la había visto, I waked, she fled, and day brought back my night (Marías, 2003: 150)15.

Y esto es lo que leemos en el citado capítulo VI:

Y si unos versos de Milton habían distraído y fortalecido la espera del advenimiento de su primer y sobreseído sino, ahora otra línea también famosa, la última del soneto sobre su ceguera, lo martirizaba mientras aguardaba, rondándolo con frecuencia como si fuera la aplicación de uno de esos castigos superfluos con los que sólo se busca una extraña equidad en cómputos insondables, la paz egoísta de quien los impone. No veía verdad en aquellas palabras: They also serve who only stand and wait (Marías, 2003: 232 - en ambas citas las cursivas son del autor).

Los versos del soneto XIX de John Milton, modificados en los sujetos de los dos verbos principales (del «they»al «we»), señalan dos diferentes posturas completamente dicotómicas: si Casaldáliga «usa» a Milton para justificar su actitud oportunista de espía a sueldo del bando franquista ${ }^{16}$, Peter Wheeler citará (modificándolos a su vez) los mismos versos para exaltar la capacidad casi-divina de los espías, que siempre «están y esperan». Berta Isla, en cambio, se adueñará por contagio citacionista de los versos del Profesor Wheeler para comparar no solo su vida o la de Tomás, sino todas las vidas humanas, con los que «solamente están y esperan». El germen que surge de un poema del siglo XVII, pasando a través de una novela del siglo XX, llega a una obra de principios del siglo XXI en la que el acto de «estar»y el de «esperar» se despojan de cualquier aura de heroicidad o de

\footnotetext{
${ }^{15}$ Milton nunca había visto a la dedicataria del soneto, esto es, a su segunda mujer Katherine Woodcock, porque, cuando se casó con ella, en 1656, ya había perdido completamente la vista. Se trata de uno de los sonetos más famosos del poeta inglés, también por la carga autobiográfica que lo caracteriza (Katherine morirá en 1658; seis semanas después morirá también el hijo que ésta le dio a Milton).

${ }^{16}$ Aunque nunca se cite explícitamente España en la novela, el protagonista se pasa los tres años que dura la guerra civil que destruye su país en Lisboa, entreteniendo la espera en meditaciones filosóficas sobre la muerte, el amor, la traición y el engaño y, sobre todo, en intentar justificar su actitud de inepto incapaz de tomar las riendas de su destino. De hecho, al finalizar la guerra, optará por trabajar a sueldo del bando ganador.
} 
religiosidad y adquieren los rasgos nihilistas de la condición humana enfocada desde un punto de vista atemporal y universal.

\section{CONCLUSIONES}

\section{Como afirma T. S. Eliot en The Use of Poetry and the Use of Criticism:}

I know that some of the poetry to which I am most devoted is poetry which I did not understand at first reading; some is poetry which I am not sure I understand yet: for instance, Shakespeare's (Eliot, 1964: 144).

Javier Marías afirma lo mismo en su artículo «Shakespeare indeciso»:

[...] una de las principales razones de la grandeza y perduración de Shakespeare es que casi nunca se sabe bien lo que está diciendo; o, si se prefiere, se sabe lo que está diciendo pero no lo que significa (Marías, 2001: 363).

Se trata de un nuevo punto de vista en común entre dos autores que, a pesar de los diferentes géneros literarios cultivados, a pesar de la distancia temporal y a pesar de las distintas poéticas que los caracterizan, hacen de la incertidumbre la fuente de inspiración de sus obras literarias; obras en las que el viaje hacia el limbo, ese territorio entre los no nacidos y los ya muertos, entre el pasado y el futuro, entre la vida y la muerte, se presenta como una fascinante forma de enfocar e intentar iluminar una parte de aquella inmensa zona de sombra en la que pervivimos y subsistimos. La novela para Marías y la poesía para Eliot son las herramientas útiles que nos ayudan a poder por lo menos acercarnos a esos misterios irresolubles. En este contexto, la literatura se convierte en un diálogo entre muertos que siguen vivos precisamente gracias a la escritura, que vuelve a dar voz a sus palabras. La intertextualidad, en cambio, lejos de convertirse en mero juego postmodernista, se configura como acto germinativo a través del cual el autor contemporáneo reescribe determinadas imágenes, versos, palabras del escritor del pasado. Los mismos personajes llegan a contaminarse a través de las citas literarias que nutren sus existencias en los momentos de más alta tensión emotiva y narrativa. 


\section{BIBLIOGRAFÍA}

Blanca, Inés (2017): Las huellas dispersas, Madrid, DeBolsillo.

Boitani, Piero (1999): Il genio di migliorare un'invenzione. Transizioni letterarie, Bologna, il Mulino.

Boitani, Piero (2014): Riconoscere è un dio, Torino, Einaudi.

Candeloro, Antonio (2016): Javier Marías y el enigma del tiempo, Murcia, Editum.

Candeloro, Antonio (2020) (en prensa): «T. S. Eliot en Oxford: Four Quartets como señal de anagnórisis en Berta Isla de Javier Marías».

Cristóbal, Vicente (2015): «Los hombres y las hojas: de Homero a Machado», Myrtia, 30: 285-289.

Curtius, Ernst Robert (2014): Literatura Europea y Edad Media Latina, México, Fondo de Cultura Económica.

de Rogatis, Tiziana (2015): «Commento e interpretazione dei Four Quartets di T. S. Eliot. Tempo cronologico, esperienza vissuta e 'illuminazione'», en Tiziana de Rogatis (ed.) (2015): La pratica del commento, Pisa, Pacini: 171-186.

Dickens, Charles (1910): A Tale of Two Cities, edición de Ashley H. Thorndike, London, Longmans, Green and Co.

Dickens, Charles (2004): Historia de dos ciudades, edición de Pilar Hidalgo, traducción al español de Juan Jesús Zaro, Madrid, Cátedra.

Eliot, Thomas Stearns (1949): Selected Essays, London, Faber \& Faber.

Eliot, Thomas Stearns (1955): Función de la crítica y función de la poesía, traducción de Jaime Gil de Biedma, Barcelona, Seix Barral.

Eliot, Thomas Stearns (1964): The Use of Poetry and the Use of Criticism, Cambridge, Harvard University Press.

Eliot, Thomas Stearns (1965): To Criticize the Critic and Other Writings, London, Faber \& Faber.

Eliot, Thomas Stearns (2002): Collected Poems 1909-1962, London, Faber \& Faber.

Harding, Jason (ed.) (2011): T. S. Eliot in Context, Cambridge, Cambridge University Press.

Hawthorne, Nathaniel (1969): The Portable Hawthorne, edición de Malcom Cowley, New York, The Viking Press.

Homero (1996): Ilíada, traducción, prólogo y notas de Emilio Crespo Güemes, Madrid, Gredos. 
Lewis, Janet (2015): El fantasma de Monsieur Scarron, traducción de Antonio Iriarte, Madrid, Reino de Redonda.

Lewis, Janet (2016): La mujer de Martin Guerre, traducción al español de Antonio Iriarte, Madrid, Reino de Redonda.

Lewis, Janet (2017): El juicio de Sören Qvist, traducción al español de Antonio Iriarte, Madrid, Reino de Redonda.

Marías, Javier (2001): Literatura y fantasma, Madrid, Alfaguara.

Marías, Javier (2003): El siglo, Madrid, Suma de Letras.

Marías, Javier (2007): Tu rostro mañana 3. Veneno y sombra y adiós, Madrid, Alfaguara.

Marías, Javier (2017): Berta Isla, Madrid, Alfaguara.

Milton, John (1990): Poetical Works, edición de Douglas Bush, Oxford, Oxford University Press.

Pérez-Carbonell, Marta (2016): The fictional world of Javier Marias. Language and uncertainty, Leiden-Boston, Rodopi.

Pittarello, Elide (2018): «Quien están y espera: Berta Isla de Javier Marías», Ínsula, 857: 4548.

Pozuelo Yvancos, José María (2018a): «Diálogo germinativo de los textos: Javier Marías ante un motivo de Juan Benet», Revista de Occidente, 450: 99-114.

Pozuelo Yvancos, José María (2018b): Novela española del siglo XXI, Madrid, Cátedra.

Segre, Cesare (1984): Teatro e romanzo, Torino, Einaudi. 


\section{Antonio Candeloro}

Licenciado en Lenguas y Literaturas Extranjeras por la Universidad «La Sapienza» de Roma; Doctor en Literaturas Extranjeras Modernas por la Universidad de Pisa. Antonio Candeloro publica en el 2011 el ensayo Como la nieve resbaladiza: Javier Marías narratore del tempo (Roma, Aracne), sobre el enigma temporal en la obra del escritor español. En el 2016 amplía el texto y publica en español Javier Marías y el enigma del tiempo (Murcia, EDITUM). Además de interesarse por la literatura española moderna y contemporánea (Juan Benet, Luis Goytisolo, Antonio Muñoz Molina, Enrique Vila-Matas), también ha publicado estudios sobre Miguel de Cervantes y las técnicas narrativas en el Quijote, además de ensayos sobre algunos autores pertenecientes a la «picaresca». En 2011 publica sendas traducciones de novelas picarescas al italiano: El siglo pitagórico y Vida de don Gregorio Guadaña (1644) de Antonio Enríquez Gómez y Las harpias en Madrid (1631) de Alonso de Castillo Solórzano (ambas aparecidas para la editorial académica ETS de Pisa y publicadas a través de los fondos de la Unión Europea en el ámbito del «Programa Cultura 2007-2013»). Profesor Titular de Filología Hispánica, actualmente imparte cursos de Didáctica de la Lengua y de la Literatura Española en la UCAM (Universidad Católica de Murcia).

\section{Contact information:}

UCAM - Universidad Católica San Antonio de Murcia

Departamento de Educación (lateral del Monasterio).

Campus de Los Jerónimos, s/n,

Guadalupe, 30107 Murcia.

Email: acandeloro@ucam.edu

Teléfono: 968278181 